\title{
WriteClick: Editor's Choice
}

Editors' Note: In response to the findings of Misawa et al. of tongue fasciculations on muscle ultrasound in $60 \%$ of patients with amyotrophic lateral sclerosis but no fasciculation potentials on EMG, Drs. Boekestein and colleagues argue that the activity might have been fibrillations. The authors disagree, countering that the movements were irregular, involved muscle bundles over $3 \mathrm{~mm}$ in diameter, and had a similar pattern and rhythm to fasciculations observed in the biceps brachii. Dr. Hellwig and colleagues question whether, in the article by Tan et al., "Immune reconstitution inflammatory syndrome in natalizumab-associated PML," the longer time between onset of symptoms and progressive multifocal leukoencephalopathy (PML) diagnosis in patients with early PML-immune reconstitution inflammatory syndrome contributed to the worse outcome in this group. They also describe the outcomes of 12 of their own patients with PML after PLEX/IA and call for further prospective studies. The authors agree with the need for continued research but cite the practical challenges of detecting and quantifying the inflammatory response in PML.

Megan Alcauskas, MD, and Robert C. Griggs, MD

\section{ULTRASONOGRAPHIC DETECTION OF}

FASCICULATIONS MARKEDLY INCREASES DIAGNOSTIC SENSITIVITY OF ALS

W.A. Boekestein, H.J. Schelhaas, J.P. van Dijk, B.U. Kleine, M.J. Zwarts, Nijmegen, the Netherlands: Using muscle ultrasound, Misawa et al. ${ }^{1}$ found fasciculations in the tongue in $60 \%$ of $81 \mathrm{pa}-$ tients with amyotrophic lateral sclerosis (ALS), whereas with EMG they detected no fasciculation potentials. This intriguing finding has been reported by Sonoo et al., ${ }^{2}$ who detected fasciculation potentials in the tongue in only 1 out of $104 \mathrm{pa}$ tients with ALS. We had the same experience.

The presumed explanation for the absence of tongue fasciculations is that complete relaxation of the tongue is rarely achieved, making it difficult to determine whether fasciculations are present. However, we suggest that "fasciculations in the tongue" are in fact fibrillations. First, what might appear as tongue fasciculations have other properties; they are highly predictable and regular, and more continuous than fasciculations seen in other muscles.

Second, looking at the tongue is looking at the muscle. Fibrillations that cannot be observed in other muscles from outside may be observed as muscle movement in the tongue. ${ }^{3}$ Third, in 1851 it was demonstrated in dogs that transsection of the hypoglossal nerve generated visible fibrillations that are intense enough to be mistaken for what are now called fasciculations. ${ }^{4}$ Muscle ultrasound is highly sensitive in detecting spontaneous activity in the bulbar region of patients with ALS. However, they are likely fibrillations instead of fasciculations.

Author Response: Sonoko Misawa, Satoshi Kuwabara, Chiba, Japan: Boekestein et al. insisted that muscle twitching in the tongue observed with ultrasonography in our study indicated fibrillations rather than fasciculations. We disagree. The muscle movement was highly irregular and involved muscle bundles over $3 \mathrm{~mm}$ in diameter that could not be caused by contraction of single muscle fibers. ${ }^{5}$ These features are very consistent with fasciculations.

Boekestein et al. also stated that fasciculations in the tongue have different properties from those in other muscles: "highly predictable and regular, and more continuous." We think that they are not true fasciculations but contraction fasciculation, nonspontaneous ongoing motor unit activity. ${ }^{6}$ As shown in the supplemental video, patterns and rhythm of fasciculations are almost identical in the tongue and biceps brachii muscle, and entirely different from those of fibrillations on muscle ultrasound previously reported. ${ }^{7}$

A prospective evaluation of ultrasound, highdensity surface EMG, concentric needle EMG, and visual inspection is required and would verify our findings.

Copyright (C) 2012 by AAN Enterprises, Inc.

1. Misawa S, Noto Y, Shibuya K, et al. Ultrasonographic detection of fasciculations markedly increases diagnostic sensitivity of ALS. Neurology 2011;77:1532-1537.

2. Sonoo M, Kuwabara S, Shimizu T, et al. Utility of trapezius EMG for diagnosis of amyotrophic lateral sclerosis. Muscle Nerve 2009;39:63-70. 
3. Pillen S, Nienhuis M, van Dijk JP, Arts IM, van Alfen N, Zwarts MJ. Muscles alive: ultrasound detects fibrillations. Clin Neurophysiol 2009;120:932-936.

4. Schiff M. Archiv f. physiologische Heilkunde 1851;10:571593. Available at: http://books.google.com.

5. Kimura J. Electrodiagnosis in Diseases of Nerve and Muscle. Philadelphia: F.A. Davis; 1983.

6. Denny-Brown D, Pennybacher JB. Fibrillation and fasciculation in voluntary muscle. Brain 1938;1:311-312.

7. Pillen S, Nienhuis M, van Dijk JP, Arts IM, van Alfen N, Zwarts MJ. Muscles alive: ultrasound detects fibrillations. Clin Neurophysiol 2009;120:932-936.

\section{IMMUNE RECONSTITUTION INFLAMMATORY SYNDROME IN NATALIZUMAB-ASSOCIATED \\ PML}

Kerstin Hellwig, Ingo Kleiter, Ralf Gold, Bo-

chum, Germany: Tan et al. ${ }^{1}$ postulated that early immunologic rebound in natalizumab-associated progressive multifocal leukoencephalopathy (PML) may implicate a worse outcome and survival. Unfortunately, the interval between the last natalizumab infusion and PLEX/IA was not provided.

Although it did not reach significance, the time between onset of symptoms and PML diagnosis was about $75 \%$ longer in those with early PML-immune reconstitution inflammatory syndrome (IRIS), which may contribute to a worse outcome. We treated 12 German PML cases and observed IRIS in all patients after PLEX/IA, but also a considerable extension of the PML lesions with development of new PML lesions in at least 4 patients. None of our 12 patients died, but one developed severe clinical deterioration and the MRI showed expanding PML lesions (without Gd enhancement in the first MRI). While IRIS seemed to be "controllable" in all our patients with repetitive pulses of corticosteroids, the only successful treatment of PML itself is to restore immunocompetence, which is more easily achieved in natalizumab-PML than in the setting of HIVassociated PML.

Therefore, a clinical, immunologic, and radiologic risk stratification for development of severe IRIS or PML deterioration is necessary to determine if there are subgroups that may profit from PLEX/IA or those who may deteriorate. Prospective studies investigating the role of PLEX/IA in the subgroup of those with Gd enhancement at the time of PML diagnosis could be helpful.

Author Response: David B. Clifford, St. Louis; Eugene O. Major, Bethesda, MD: We agree with Hellwig et al. that prospective and critical analysis of the benefits and risks of PLEX/IA is highly desirable. The practical aspects of such investigations are extremely challenging, particularly because clinically significant inflammatory responses to PML are difficult to quantify, and are occurring in some cases even before contrast enhancement is detected on MRI scans. Consequently, it is not possible to know whether JC virus-driven oligodendrocyte lysis giving advancing PML or a damaging inflammatory response is causing progressive symptoms and changes on MRI scans. While the improved survival in PML cases in natalizumab-associated PML supports the current recommendations to routinely provide PLEX to remove natalizumab and activate immune surveillance in the brain, it would be very useful to develop the means to select populations where more gradual immune reconstitution might be preferred.

Copyright (c) 2012 by AAN Enterprises, Inc.

1. Tan IL, McArthur JC, Clifford DB, Major EO, Nath A. Immune reconstitution inflammatory syndrome in natalizumab-associated PML. Neurology 2011;77:1061-1067.

\section{CORRECTION}

PRION-1 scales analysis supports use of functional outcome measures in prion disease

In the article "PRION-1 scales analysis supports use of functional outcome measures in prion disease" by S. Mead et al. (Neurology ${ }^{\circledR} 2011 ; 77: 1674-1683$ ), there is an omission in the Acknowledgment. The authors also gratefully acknowledge the contribution of National Prion Clinic physicians Drs. Tom Webb, Suvankar Pal, and Durre Siddique. The authors regret the omission. 


\section{Neurology}

\section{Ultrasonographic Detection of Fasciculations Markedly Increases Diagnostic Sensitivity of ALS}

W.A. Boekestein, Sonoko Misawa, H.J. Schelhaas, et al. Neurology 2012;78;370-371

DOI 10.1212/WNL.0b013e3182475368

This information is current as of January 30, 2012

\section{Updated Information \&} Services

References

Permissions \& Licensing

Reprints including high resolution figures, can be found at: http://n.neurology.org/content/78/5/370.full

This article cites 6 articles, 1 of which you can access for free at: http://n.neurology.org/content/78/5/370.full\#ref-list-1

Information about reproducing this article in parts (figures,tables) or in its entirety can be found online at:

http://www.neurology.org/about/about_the_journal\#permissions

Information about ordering reprints can be found online: http://n.neurology.org/subscribers/advertise

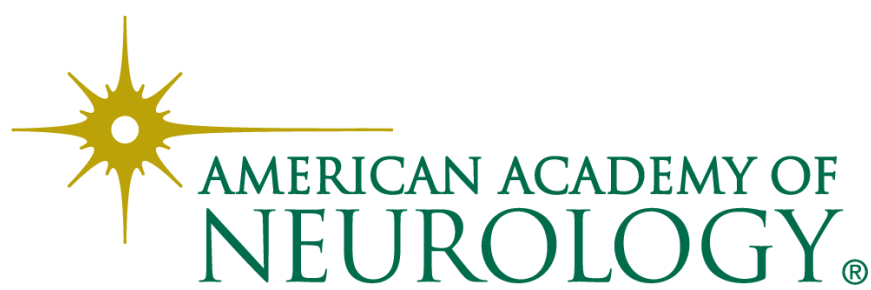

